\title{
Temporal And Spatial Changes In Cerebral Blood Flow In Neuropsychiatric Systemic Lupus Erythematosus: A Subtraction Brain Spect Study.
}

\author{
Ana Carolina Trevisan ( $\square$ acstrevisan@usp.br) \\ Nuclear Medicine and PET/CT Laboratory. Ribeirão Preto Medical School, University of São Paulo https://orcid.org/0000-0003-0876-0269 \\ Leonardo Alexandre-Santos \\ Nuclear Medicine and PET/CT Laboratory, Department of Medical Imaging, Hematology and Clinical Oncology, Ribeirão Preto Medical School, University of \\ São Paulo, Ribeirão Preto, Brazil.

\section{Rodrigo Luppino-Assad} \\ Ribeirao Preto University: Universidade de Ribeirao Preto

\section{Emerson Nobuyuki Itikawa} \\ Physics Institute, Federal University of Goiás, Goiás, Brazil.

\section{Felipe Arriva Pitella} \\ Nuclear Medicine and PET/CT LAboratory, Department of Medical Imaging, Hematology and Clinical Oncology, Ribeirão Preto Medical School, University of \\ São Paulo, Ribeirão Preto, Brazil

\section{Mery Kato} \\ Nuclear Medicine and PET/CT LAboratory, Department of Medical Imaging, Hematology and Clinical Oncology, Ribeirão Preto MEdical School, University of \\ São Paulo, Ribeirão Preto, Brazil. \\ José Henrique Silvah \\ Nuclear Medicine and PET/CT LAboratory, Department of Medical Imaging, Hematology and Clinical Oncology, Ribeirão Preto Medical School, University of \\ São Paulo, Ribeirão Preto, Brazil.

\section{Antonio Carlos Santos} \\ Magnetic Resonance Laboratory, Department of Medical Imaging, Hematology and Clinical Oncology, Ribeirão Preto Medical School, University of São Paulo, \\ Ribeirão Preto, Brazil. \\ Paulo Louzada-Junior \\ Division of Rheumatology, Departmente os Internal Medicine, Ribeirão Preto Medical School, University of São Paulo, Ribeirão Preto, Brazil. \\ Lauro Wichert-Ana \\ Nuclear Medicine and PET/CT Laboratory, Department of Medical Imaging, Hematology and Clinical Oncology, Ribeirão Preto Medical School, University of \\ São Paulo, Ribeirão Preto, Brazil.
}

\section{Original article}

Keywords: Systemic Lupus Erythematosus, Neuropsychiatric Form, Brain SPECT, SISCOM

Posted Date: July 8th, 2021

DOI: https://doi.org/10.21203/rs.3.rs-646612/v1

License: @ (i) This work is licensed under a Creative Commons Attribution 4.0 International License. Read Full License 


\section{Abstract}

This study was addressed to evaluate the temporal and spatial changes in regional cerebral blood flow (rCBF) of patients with neuropsychiatric systemic lupus erythematosus (NPSLE). Our objective was to correlate the subtracted SPECT coregistered to MRI features (SISCOM) with demographic, clinical and laboratory findings to shed light upon the pathophysiological evolution of the NPSLE.

Twenty-six NPSLE patients with MRI and pre and post-treatment brain SPECT with [99mTc]Tc-ECD. SISCOM features were categorized as improvement,worsening, activation and/or deactivation of rCBF findings.

Patients mean age of 43.19 years and $65.38 \%$ white were evaluated. The patients mean age at onset of SLE was 26.05 and 42.29 for NPSLE. The mean time between the onset of SLE and first NPSLE symptoms was 5.57 years. The disease has already been initiated as NPSLE in 4 patients. The SLEDAl average score was 31.69 and the SLICC/ACR-DI score was 6.96. The patients underwent an average of 9.23 cyclophosphamide. The SISCOM findings showed functional and pathological states on different brain regions. The rCBF changes were not associated with index scores. There was, however, a trend towards an association between lower SLEDAI scores with improvement and higher SLEDAI with worsening in SISCOM. Also, a trend of association between lower SLICC score with improvement, and higher SLICC with worsening. The female gender was predictive of activation and worsening, separately, and deactivation and worsening in a set. Non-white patients were predictive of worsening. The seizure was predictive of deactivation separately, and deactivation and worsening in a set. Finally, normal C3 was a predictor of improvement.

The present study showed dynamic brain changes in NPSLE patients. SISCOM technique showed improved rCBF in some brain areas, and worsening, activation and deactivation in anothers. There were associations between rCBF changes and gender, skin colour and complement C3, and association trends with SLEDAI and SLICC scores.

\section{Introduction}

The Systemic Lupus Erythematosus (SLE) is an inflammatory autoimmune disease that targets many organs and systems, including the nervous system. Neuropsychiatric Systemic Lupus Erythematosus (NPSLE) can affect 12-75\% of SLE patients and involve both central and peripheral nervous systems. Cognitive dysfunctions are the most common manifestations, followed by psychosis or mood disorder, cerebrovascular disease, convulsions and headaches. [1][2]. Although neuropsychiatric (NP) manifestations are frequent, they still constitute a challenge for behavioral and neuroimaging studies. [3] NP manifestations can precede the onset of SLE or occur at any time during its course [4], and can be single or multiple neurological events in the same individual. [5] The two most important processes under the etiological aspect of NPSLE are changes in rCBF due to the occlusion of vessels that irrigate the nervous tissue, or interactions of autoantibodies with neurons and glia. [6] Despite the efforts to determine the diagnosis of NPSLE, there is still no standard gold method for the diagnosis and management of the symptoms presented. [7] [8]

The ACR committee responsible for the classification of syndromes in NPSLE considers that structural (Magnetic Resonance Imaging, MRI) and functional brain imaging (Single Photon Emission Computed Tomography, SPECT) may become the gold standard method for the classification of NPSLE and are essential components in some case definitions [5]. The MRI is widely used to evaluate NPSLE patients, presenting variable sensitivity, being abnormal in 15.0 to $78.0 \%$ of patients, and having low specificity, being abnormal in 25.0 to $50.0 \%$ of patients with SLE, without NP manifestation. [9] It is quite useful in cases of focal impairment of NPSLE [10], and less effective in cases of diffuse involvement. [11]. Another significant limitation is the difficult differentiation between new or active from old or sequel injuries.

The brain SPECT evaluates the regional cerebral blood flow (rCBF) and contributes to diagnosing cerebrovascular diseases, dementia, epilepsy, movement disorders, and psychiatric, vascular, and degenerative diseases. [12] It has been known that immune dysfunction in active SLE affects the brain by different mechanisms, either presence of circulating autoantibodies, entry of pro-inflammatory cytokines and chemokines into the cerebrospinal fluid or even the rupture of the blood-brain barrier [13]. Brain SPECT has shown abnormalities in the central nervous system (CNS) in the SLE [7], with a higher correlation with clinical findings in NPSLE, than MRI. The most common SPECT findings in NPSLE patients are focal, diffuse or multifocal areas of decreased rCBF, related to the severity and activity of NPSLE. Lesions are commonly seen in middle cerebral artery territory, followed by parietal, frontal, and temporal lobes, and basal ganglia. [14] In the context of the pathophysiological investigation, the subtraction ictal SPECT co-registered to MRI (SISCOM) can be used beyond epilepsy, and may contribute to the temporal evaluation of brain injuries by NPSLE. [15] Only case reports have shown the role of SISCOM in NPSLE. [16] The presence of SPECT changes with normal MRI may be predictive of CNS involvement even in the absence of current NP manifestations. [9]

This study was addressed to evaluate the temporal and spatial changes in regional cerebral blood flow of patients with NPSLE. Our objective was to correlate SISCOM features with demographic, clinical and laboratory findings to shed light upon the pathophysiological evolution of the NPSLE.

\section{Patients And Methods}

\section{Patients}

Twenty-six patients with NPSLE were evaluated by the Rheumatology division and the Nuclear Medicine and PET/CT Laboratory of our university hospital. All patients were diagnosed by the criteria of the SLICC/ACR-DI (Systemic Lupus International Collaborating Clinics/American College of Rheumatology - Damage Index), and the disease activity was assessed by the SLEDAI index (Systemic Lupus Erythematosus Disease Activity Index). All patients underwent brain SPECT with [ ${ }^{99 \mathrm{~m} T c] T c-E C D}$ pre and post-Cyclophosphamide and Methylprednisolone pulse therapy and in time close to the brain MRI.

\section{Clinical, MRI and Laboratory Exams}


All patients underwent clinical examinations, determination of anti-DNA antibodies and antinuclear factor antibody (FAN), and the majority of patients to the levels of serum complement C3 and C4, anti-P-ribosomal (P0, P1, P2), anti-Sm and anti-Sm/RNP antibodies, anti-SS-A (RO) and anti-SS-B (LA) antibodies, IgG and IgM anticardiolipin antibodies, b2-glycoprotein I (b2GPI)-dependent, anti-Chromatin antibody, anti-Nucleosome IgG antibody, anti-TPO antibody antiPeroxidase and anti-ß2-glycoprotein-I (B2-GPI).

MRI was acquired using the 3.0-T MRI system Philips Achieva (Philips Medical Systems, Best, The Netherlands), between 2010 and 2019 , according to protocols specifically designed for brain studies: Dual echo FSE (fast spin echo) with $1 \mathrm{~mm}$ slice thickness, 3D T1-weighted, high-resolution 3D T1-weighted 3D MPRAGE, 3D T2-weighted images, 3D fast T2-weighted FLAIR with fat suppression, axial T2-weighted TSE, DWI (diffusion weighted imaging), axial SWI (susceptibility weighted magnetic resonance imaging), non-contrast-enhanced 3D TOF MRA (magnetic resonance angiography).

SPECT protocol

All patients underwent brain SPECT after the intravenous injection of 1,110 MBq (30 mCi) of the tracer Technetium-99m Ethyl Cysteinate Diethyl Ester ([99m Tc]Tc-ECD). Injection was performed when patients were at rest, with eyes open, in a quiet and darkroom, refrained from moving, talking and listening. SPECT scans were acquired in a double-headed SPECT/CT Philips Brightview XCT (Philips Healthcare, Cleveland, Ohio, USA), with a low energy highresolution collimator (LEHR), photopeak centered on $140 \mathrm{keV}$ and acceptance window of $20 \%, 64$ projections per head over $360^{\circ}$, on a $128 \times 128$ matrix, acquisition time of $30 \mathrm{~min}$, and about 100,000 counts/projection/head. Projections were reconstructed using the Ordered Subset Expectation Maximization (OSEM), applying Butterworth filter (order 2, cutoff frequency 0.28 ), and photon attenuation correction by uniform method (Chang, pixel size 2.13, coefficient $0.12 / \mathrm{cm})$. Images were then reconstructed in transaxial slices parallel to the orbito-meatal line, from which coronal and sagittal sections were produced.

\section{SISCOM analysis}

The SISCOM was performed using the ANALYZE @ 10.0 Software (AnalyzeDirect, Inc., Overland Park, Kansas, USA), following the methodology adapted from previous studies [17]. The 1st and 2nd SPECTs, whether pre and post-treatment, or performed between different clinical pictures, were registered using an alignment algorithm based on mutual information. The 1st SPECT was subtracted from the 2nd one, and the signal difference was transformed into z-score maps, using the mean and standard deviation of the differences in all brain voxels, resulting in images of increase or decrease of rCBF. This quantification matrix was fused with the patient's MRI, in order to provide functional and anatomical information in the same image. After functional overlap, only images with significant rCBF changes, i.e., more than 2 standard deviations above or below the mean, were exhibited.

SISCOM findings were classified into four groups. Improvement was the group of patients who presented increased rCBF in the 2nd SPECT on brain regions that showed decreased rCBF in the 1st SPECT. Clinically, it means a reperfusion of an ischemic or hypofunctioning brain region after treatment. Worsening was the group with decreased rCBF in the 2nd SPECT on a brain region with normal rCBF in the 1 st SPECT. Clinically, it means an ischemic insult or hypofunctioning status of a brain region after treatment. Activation was the group with increased rCBF in the 2nd SPECT on a brain region that presented normal rCBF in the 1st SPECT. Clinically, it means a previously normal brain region that evolved to hyperemia or hyperfunctioning status after treatment. Deactivation was the group with increased rCBF in the 1st SPECT on a brain region that presented normal rCBF in the 2nd SPECT. Clinically, it means a previously hyperemic or hyperfunctioning brain region that evolved to normal status after treatment.

\section{Statistical analysis}

Statistical analysis was performed using IBM SPSS Statistics for Windows, Version 23 (IBM SPSS Statistics for Windows, Launched in 2015, IBM Corporation, Armonk, NY, USA). Binary logistic regression analyzed if clinical, laboratory and complement (C3 and C4) variables were predictive of SISCOM findings. Only the variables that showed significant differences between patients with normal and abnormal evolution $(p<0.05)$ were evaluated. The Mann-Whitney test (Wilcoxon rank-sum test) analyzed whether there were significant differences between nonparametric variables $(p<0.05)$.

\section{Results}

\section{Demographic data}

The table summarizes demographic and clinical features of the NPSLE patients. Twenty-six patients (19 females, $73.07 \%$; 7 males, $26.93 \%$ ), with mean age of 43.19 years (SD 11.33; 95\% Cl 38.61-47.77), ranging from 20 to 70 years, were evaluated. Sixteen women had normal pregnancy (69.56\%), one had abortion (4.36\%), and six were nulliparous (26.08\%). Most patients were self-declared white $(n=17 ; 65.38 \%)$, followed by mixed race, brown color, and black (non-white; $\mathrm{n}=9 ; 34.62 \%$ ). The patient's mean age at onset of SLE was 26,05 (SD 11,04) years, ranging from 8 to 51 years, and for NPSLE was 42.29 (SD 13,49$)$ years, ranging from 11 to 59 years. The mean time between the onset of SLE and first NPSLE symptoms was 5.57 (SD 5.02 ) years, ranging from zero to 22 years. The disease has already been initiated as NPSLE in 4 patients (15.38\%).

\section{Clinical and laboratory data}

The average score on SLEDAI was 31.69 (SD 10.33; 95\% Cl 27.51-35.86), ranging from 11 to 51 scores, and the SLICC/ACR-DI score was 6.96 (SD 2.37; $95 \%$ $\mathrm{Cl}$ 6.00-7.92), ranging from 2 to 11 scores. The patients underwent an average of 9.23 pulse therapy sessions (SD 3.12; $95 \% \mathrm{Cl} 7.96-10.49)$, ranging from 4 to 15 sessions.

Seventeen 17 (65.38\%) patients presented psychosis, 01 (3.84\%) bipolar disorder, 07 (26.92\%) depression, 02 (7.69) vasculitis, 08 (30.77) seizure, 06 (23.07) anxiety, 02 (7.69) headache, 01 (3.84) epilepsy and 01 (3.84) stroke.

All patients underwent Native anti-DNA and ANA laboratory tests. For Native anti-DNA and ANA, 13 (50\%) and 19 (73.07\%) patients were reactive, respectively. For ACA IgG and IgM, nine (30.76\%) and 13 (50.09\%) patients were positive, respectively. For anti- $\beta 2 \mathrm{GPI} \lg$ and IgM, five (31.25\%) and seven (43.75\%) 
patients were positive, respectively. For anti-SS-B (LA) and anti-SS-A (RO), one (14.29\%) and three (30.00\%) patients were also positive, respectively. Complement levels were altered in 11 (42.31\%) patients for $\mathrm{C} 3$, and in $8(30.77 \%)$ for $\mathrm{C} 4$.

\section{SISCOM findings}

The MRI was normal in $6(23.08 \%)$ patients and abnormal or with nonspecific findings in another 20 (76.92\%). SISCOM agreed with MRI findings in 13 patients $(50.00 \%)$. None of the NP manifestations correlated with the SISCOM findings. le., the evolution of rCBF changes (SISCOM) was not influenced by the type of NP manifestation.

Regarding the SISCOM findings, 15 (57.69\%) patients presented improvement, 12 (46.15\%) activation, 8 (30.77\%) deactivation and 6 (23.07\%) presented worsening. These categories were not associated with the degree of activity [SLEDAl, Mann Whitney Test; improvement, $\mathrm{U}=60.5000, \mathrm{p}=0.252 ;$ activation, $\mathrm{U}=$ $66,000, p=0.353$; deactivation, $U=51,500, p=0.254$ and worsening, $U=51,000, p=0.583$ ] or disease-related damage [SLICC, Mann Whitney Test; improvement, $U=65,500, p=0.371$; activation, $U=67,000, p=0.375$; deactivation, $U=47,500, p=0.167$ and worsening, $U=56,000, p=0.805]$. However, there was a trend towards an association between lower disease activity (SLEDAI 33.80) and improvement, and greater activity (SLEDAI 35.00) with worsening [Mann Whitney test, $U=56,000 ; p=0.072$ ]. There was also a trend of association between lower damage associated with LESNP (SLICC 6.73) with improvement, and greater damage (SLICC 7.83) with worsening rCBF (Mann Whitney test, $U=56,000, p=0.085$ ).

Binary logistic regression showed that the model containing female gender was significant for activation $[X 2(1)=5.804 ; p=0.041, R 2$ Negelkerke $=0.267]$ and worsening $[X 2(1)=9.781 ; p=0.008, R 2$ Negelkerke $=0.475]$ in SISCOM, but not significant for amelioration and deactivation. The female gender was predictive of activation (OR $=0.091$; IC $95 \%=0.009-0.906)$ and worsening $(O R=28.333$; IC $95 \%=2.389-336.008)$, but not predictive of amelioration or deactivation. The model containing female gender was also significant for the finding set of deactivation and worsening [X2 (1) = 5.804; $p=0.041, R 2$ Negelkerke $=0.282$, but not significant for the set of activation and worsening. The female gender was predictive of the deactivation and worsening set $(\mathrm{OR}=$ $11,000 ;$ IC $95 \%=1,103-109,674)$, and not predictive of the activation and worsening set.

Binary logistic regression showed that the model containing non-white races was significant for worsening in the SISCOM [X2 (1) $=7,279 ; \mathrm{p}=0.020, \mathrm{R} 2$ Negelkerke $=0.387$, but not for amelioration, activation or deactivation. Non-white races were predictive of worsening in SISCOM $(O R=17,500 ;$ IC $95 \%=1,560$ -196,319), but not predictive of improvement, activation or deactivation.

Binary logistic regression of the 24 patients who measured the presence of complement $\mathrm{C} 3$ showed that the model containing the normal result (RV $0.9-1.4 \mathrm{U}$ / $\mathrm{ml}$ ) was significant for improvement in SISCOM [X2 (1) = 7.279; $\mathrm{p}=0.021$, R2 Negelkerke $=0.303]$, but not for the worsening, activation or deactivation. Normal C3 was a significant predictor of improvement in SISCOM (OR =8,889; IC 95\% = 1,397-56,575), but not for worsening, activation or deactivation. Normal C4 was not a significant predictor of any SISCOM finding.

Binary logistic regression of the NP manifestations showed a trend between seizure and deactivation and worsening group [X2 (1) $=3.798 ; \mathrm{p}=0.062, \mathrm{R} 2$ Negelkerke $=0.185 ; \mathrm{OR}=5.133 ; \mathrm{IC} 95 \%=0.922-28.570]$ and deactivation group $[X 2(1)=3.665 ; \mathrm{p}=0.096, \mathrm{R} 2 \mathrm{Negelkerke}=0.185 ; \mathrm{OR}=7.000 ; \mathrm{IC} 95 \%=0.709-$ 69.121], but not for the amelioration, activation and worsening.

\section{Discussion}

The present study evaluated the temporal and spatial changes of rCBF through subtracted serial brain SPECT in patients with NPSLE. The SISCOM findings showed functional (activation, deactivation) and pathological (improvement, worsening) states on different brain regions. The rCBF changes were not associated with SLEDAI or SLICC scores. There was, however, a trend towards an association between lower SLEDAI score with improvement, and higher SLEDAI with worsening in SISCOM; also, a trend of association between lower SLICC score with improvement, and higher SLICC with worsening in SISCOM. The female gender was predictive of activation and worsening, separately, and deactivation and worsening in a set. Non-white races were predictive of worsening in SISCOM. Finally, normal C3 was a predictor of improvement in SISCOM after treatment.

The SISCOM showed that $57.69 \%$ of patients presented improvement, $46.15 \%$ activation, $30.77 \%$ deactivation, and $23.07 \%$ presented worsening of rCBF. These findings agreed with MRI in only $50 \%$ of patients. None of the neuropsychiatric manifestations correlated with the SISCOM findings. A correlation between focal lesions on MRI and areas of decreased rCBF in SPECT have been reported in $38.70 \%$ of patients with LESNP, and a lack of correlation in $61.29 \%$ [18]. A previous study showed decreased rCBF in $90 \%$ of patients with NPSLE and in $20 \%$ of patients with SLE only. [19] Most SPECT changes have been observed before treatment, notably in the parietal lobes (91.70\%) and less in the cerebellum (25.00\%), with complete recovery of rCBF after therapy in $83.30 \%$ of NPSLE patients [20]. Nine of our 26 patients presented decreased rCBF in parietal lobes that evolved to normal rCBF in 8 (88.88\%) after treatment. In NPSLE patients, bilateral decreased rCBF was found in frontal lobes in up to $81.10 \%$ of patients with cognitive impairment [21], and decreased rCBF in the precuneus in those with memory impairment. [22] Previously, we reported an aphasic female NPSLE patient who evolved with reperfusion in the Broca's area after a vasculitic insult, documented by SISCOM. [16].

The effect of gender on NPSLE may be related to genetic and environmental factors [23][24], and female sex hormones (estrogen), on the immune system [25]. The female predominance is 9:1 [26][27], but in our study it was 3:1. Our female sample showed more functional activation in the 2nd SPECT, and consequently in SISCOM, but with decreased rCBF compared to the male sample. This finding contrasts previous studies where men with SLE form an unusual group of inflammatory disease, more aggressive, with acute psychosis and seizure, and more severe sequelae than women [28][29][26].

The incidence and prevalence of SLE are higher in non-Caucasian (African, African-American and Hispanic) than Caucasian (white) races [25][28]. Our nonwhite patients showed worsening $\mathrm{rCBF}$ in SISCOM compared to white. Genetic studies point to genetically determined ancestry and environmental factors as 
responsible for these ethnicity-related biological processes [30]. There has been a considerable increase in SLE rates in non-white patients recently, which may increase diagnostic and therapeutic challenges [31].

Complement $\mathrm{C} 3$ is a complex system of proteins associated with cell membranes, contributing to the clearance of immune complexes and inflammatory processes. C3 deficiency is associated with severe inflammatory tissue destruction in NPSLE [32, 33]. This deficiency compromises the activities related to opsonization and phagocytosis, causing greater susceptibility to infections and being related to the worsening of NPSLE. Thus, normal C3 dosage favors the improvement of the inflammation process in these patients. [33] In our study, normal C3 was interestingly associated with improved rCBF in SISCOM, confirming the role of $\mathrm{C} 3$ in the resolution of neuroinflammation in NPSLE.

\section{Limitations of the study}

In our study, the lack of correlation between SISCOM findings and neuropsychiatric manifestations, and only trends of association between the SLEDAI and SLICC scores with SISCOM may be due to the small sample of patients. It was not possible to compare our NPSLE patients with those with only SLE. Our study was retrospective and the SPECT was successfully used for more than a decade to evaluate NPSLE patients only.

\section{Conclusions}

The present study showed dynamic brain changes in cerebral blood flow in NPSLE patients. SISCOM technique showed improved rCBF in some brain areas, and worsening, activation and deactivation in anothers. There were associations between rCBF changes and gender, races and complement C3, and association trends with SLEDAI and SLICC scores. Future studies should correlate these rCBFs with neuropsychiatric symptoms in larger samples, and perform clinical trials that evaluate the efficacy of therapies in light of rCBF changes.

\section{Declarations}

\section{ETHICS APPROVAL AND CONSENT TO PARTICIPATE}

As the project data were retrospective, the application of the free and informed consent term was waived in accordance with the ethical standards of the institutional and national research committee.

\section{CONFLICT OF INTEREST}

Author Ana Carolina Trevisan declares that she has no conflict of interest.

Author Leonardo Alexandre Santos declares that he has no conflict of interest.

Author Rodrigo Luppino Assad declares that he has no conflict of interest.

Author Emerson Nobuyuki Itikawa declares that he has no conflict of interest.

Author Felipe Arriva Pitella declares that he has no conflict of interest.

Author Mery Kato declares that she has no conflict of interest.

Author José Henrique Silvah declares that he has no conflict of interest.

Author Antonio Carlos Santos declares that he has no conflict of interest.

Author Paulo Louzada-Junior declares that he has no conflict of interest.

Author Lauro Wichert-Ana declares that he has no conflict of interest.

\section{CONSENT FOR PUBLICATION}

Not applicable

\section{AVAILABILITY OF DATA AND MATERIAL}

All data generated or analysed during this study are included in this published article [and its supplementary information files].

\section{COMPETING INTERESTS AND NO FUNDING CASE}

None of funding agencies played a role in the design, data collection, management, analysis, interpretation of the data, and preparation, review or approval of the manuscript. We confirm that we have read the journal's position on issues involved in ethical publication and affirm that this study has the approval of our institutional ethics committee.

\section{AUTHOR'S CONTRIBUTIONS}


All authors listed have contributed sufficiently to the investigation of the patient evaluation and to this manuscript writing be included as authors. In details, they contributed evaluating and investigating the images, performing the critical analysis of SISCOM reconstruction, processing and analyzing SPECT AND MRI and drafting the article, revising it critically for important intellectual content and final approval of the version to be published (all authors).

\section{ACKNOWLEDGEMENTS}

We are grateful to all of the SLE patients for the image. We thank Dr. Lauro Wichert-Ana for advice and encouragement. This work was supported University of São Paulo and Rheumatology and Radiology section of Medical School in Ribeirão Preto, Brazil.

\section{References}

1. Jafri K, Patterson SL, Lanata C. Central Nervous System Manifestations of Systemic Lupus Erythematosus. Rheum Dis Clin North Am [Internet]. 2017;43(4):531-45. Available from: http://dx.doi.org/10.1016/j.rdc.2017.06.003

2. Govoni M, Bortoluzzi A, Padovan M, Silvagni E, Borrelli M, Donelli F et al (2016 Nov;74:41-72) The diagnosis and clinical management of the neuropsychiatric manifestations of lupus. J Autoimmun [Internet]. Available from: http://dx.doi.org/10.1016/j.jaut.2016.06.013

3. Netto TM, Zimmermann N, Rueda-Lopes F, Bizzo BC, Fonseca RP, Gasparetto EL (2013 May;40(3):284-91) Neuropsychiatric lupus: classification criteria in neuroimaging studies. Can J Neurol Sci [Internet]. Available from: http://dx.doi.org/10.1017/s0317167100014219

4. van Dam AP, Wekking EM, Callewaert JAC, Schipperijn AJM, H A P, de Jong J et al. Psychiatric symptoms before systemic lupus erythematosus is diagnosed. Rheumatol Int [Internet]. 1994;14(2):57-62. Available from: http://dx.doi.org/10.1007/bf00300248

5. The American College of Rheumatology nomenclature and case definitions for neuropsychiatric lupus syndromes. Arthritis Rheum [Internet]. 1999 Apr;42(4):599-608. Available from: http://dx.doi.org/10.1002/1529-0131(199904)42:4<599::AID-ANR2>3.0.CO;2-F

6. Hirohata S (2018) Pathology of Neuropsychiatric Systemic Lupus Erythematosus. In: Neuropsychiatric Systemic Lupus Erythematosus [Internet]. p. 4358. Available from: http://dx.doi.org/10.1007/978-3-319-76496-2_4

7. Appenzeller S, Amorim BJ, Ramos CD, Rio PA, de C Etchebehere, Camargo ECS EE, et al. Voxel-based morphometry of brain SPECT can detect the presence of active central nervous system involvement in systemic lupus erythematosus. Rheumatology [Internet]. 2007 Mar;46(3):467-72. Available from: http://dx.doi.org/10.1093/rheumatology/kel255

8. Castellino G, Bortoluzzi A, Padovan M, Borrelli M, Feggi L, Govoni M (2011 Nov;20(13):1387-95) Repeated brain conventional MRI and SPECT evaluation in systemic lupus erythematosus patients with and without neuropsychiatric involvement: a follow up study. Lupus [Internet]. Available from: http://dx.doi.org/10.1177/0961203311415304

9. Zardi EM, Taccone A, Marigliano B, Margiotta DPE, Afeltra A (2014 Aug;13(8):831-9) Neuropsychiatric systemic lupus erythematosus: tools for the diagnosis. Autoimmun Rev [Internet]. Available from: http://dx.doi.org/10.1016/j.autrev.2014.04.002

10. Tan Z, Zhou Y, Li X, Wang G, Tao J, Wang L et al (2018 Jan;37(1):227-33) Brain magnetic resonance imaging, cerebrospinal fluid, and autoantibody profile in 118 patients with neuropsychiatric lupus. Clin Rheumatol [Internet]. Available from: http://dx.doi.org/10.1007/s10067-017-3891-3

11. Levy RA, de Carvalho JF. Lupus and the brain: neuropsychiatric aspects in systemic lupus erythematosus. Lupus [Internet]. 2017;26(5):451-2. Available from: http://dx.doi.org/10.1177/0961203317700487

12. Matsumoto Y, Oikawa K, Nomura J-I, Kojima D, Oshida S, Kobayashi M et al (2017 Jul;42(7):499-505) Optimal Brain 99mTc-Ethyl Cysteinate Dimer SPECT Imaging and Analysis to Detect Misery Perfusion on 150 PET Imaging in Patients With Chronic Occlusive Disease of Unilateral Major Cerebral Artery. Clin Nucl Med [Internet]. Available from: http://dx.doi.org/10.1097/RLU.0000000000001670

13. Duarte-Delgado NP, Vásquez G, Ortiz-Reyes BL (2019) Blood-brain barrier disruption and neuroinflammation as pathophysiological mechanisms of the diffuse manifestations of neuropsychiatric systemic lupus erythematosus [Internet]. Vol. 18, Autoimmunity Reviews. p. 426-32. Available from: http://dx.doi.org/10.1016/j.autrev.2018.12.004

14. Long Z, Hanson DP, Mullan BP, Hunt CH, Holmes DR 3rd, Brinkmann BH et al. Analysis of Brain SPECT Images Coregistered with MRI in Patients with Epilepsy: Comparison of Three Methods. J Neuroimaging [Internet]. 2018 May;28(3):307-12. Available from: http://dx.doi.org/10.1111/jon.12496

15. Aupy J, Wongwiangjunt S, Wang ZI, Wu G, Alexopoulos A. Subcortical SISCOM hyperperfusion: Should we pay more attention to it? Seizure [Internet] (2018 Nov;62:43-8) Available from: http://dx.doi.org/10.1016/j.seizure.2018.09.017

16. Trevisan AC, Louzada P Jr, Pitella FA, Kato M, Santos AC, Wichert-Ana L. The Reperfusion of Ischemic Vasculitis in a Patient with Neuropsychiatric Lupus: A Serial Single-Photon Emission Computed Tomography Study. Indian J Nucl Med [Internet]. 2019 Apr;34(2):167-8. Available from: http://dx.doi.org/10.4103/ijnm.IJNM_135_18

17. Wichert-Ana L, de Azevedo-Marques PM, Oliveira LF, Fernandes RMF, Velasco TR, Santos AC et al. Ictal technetium-99 m ethyl cysteinate dimer singlephoton emission tomographic findings in epileptic patients with polymicrogyria syndromes: a subtraction of ictal-interictal SPECT coregistered to MRI study. Eur J Nucl Med Mol Imaging [Internet]. 2008 Jun;35(6):1159-70. Available from: http://dx.doi.org/10.1007/s00259-007-0655-3

18. Oku K, Atsumi T, Furukawa S, Horita T, Sakai Y, Jodo S et al (2003 Jun;42(6):773-7) Cerebral imaging by magnetic resonance imaging and single photon emission computed tomography in systemic lupus erythematosus with central nervous system involvement. Rheumatology [Internet]. Available from: http://dx.doi.org/10.1093/rheumatology/keg216

19. Huang WS, Chiu PY, Tsai CH, Kao A, Lee CC (2002 Sep;22(5):178-81) Objective evidence of abnormal regional cerebral blood flow in patients with systemic lupus erythematosus on Tc-99m ECD brain SPECT. Rheumatol Int [Internet]. Available from: http://dx.doi.org/10.1007/s00296-002-0224-9

20. Liu FY, Huang WS, Kao CH, Yen RF, Wang JJ, Ho ST. Usefulness of Tc-99m ECD brain SPECT to evaluate the effects of methylprednisolone pulse therapy in lupus erythematosus with brain involvement: a preliminary report. Rheumatol Int [Internet]. 2003 Jul;23(4):182-5. Available from:

Page $6 / 10$ 
http://dx.doi.org/10.1007/s00296-002-0282-z

21. Driver CB, Wallace DJ, Lee JC, Forbess CJ, Pourrabbani S, Minoshima S et al. Clinical validation of the watershed sign as a marker for neuropsychiatric systemic lupus erythematosus. Arthritis Rheum [Internet]. 2008 Mar 15;59(3):332-7. Available from: http://dx.doi.org/10.1002/art.23308

22. Oh DH, Kim SH, Jung S, Sung Y-K, Bang S-Y, Bae S-C et al. Precuneus hypoperfusion plays an important role in memory impairment of patients with systemic lupus erythematosus. Lupus [Internet]. 2011 Jul;20(8):855-60. Available from: http://dx.doi.org/10.1177/0961203310394895

23. Ginzler EM, Dooley MA (2014) Systemic lupus erythematosus. Rheum Dis Clin North Am [Internet]. Aug;40(3):xiii - xiv. Available from: http://dx.doi.org/10.1016/j.rdc.2014.05.004

24. Isenberg DP (2012) Psychotherapy Outcome Kit [Internet]. PsycTESTS Dataset. Available from: http://dx.doi.org/10.1037/t06490-000

25. O’Neill S, Cervera R (2010) Systemic lupus erythematosus [Internet]. Vol. 24, Best Practice \& Research Clinical Rheumatology. p. 841-55. Available from: http://dx.doi.org/10.1016/j.berh.2010.10.006

26. Falasinnu T, Chaichian Y, Bass MB, Simard JF (2018) The Representation of Gender and Race/Ethnic Groups in Randomized Clinical Trials of Individuals with Systemic Lupus Erythematosus. Curr Rheumatol Rep [Internet]. Mar 17;20(4):20. Available from: http://dx.doi.org/10.1007/s11926-018-0728-2

27. Nusbaum JS, Mirza I, Shum J, Freilich RW, Cohen RE, Pillinger MH et al (2020 Feb;95(2):384-94) Sex Differences in Systemic Lupus Erythematosus: Epidemiology, Clinical Considerations, and Disease Pathogenesis. Mayo Clin Proc [Internet]. Available from:

http://dx.doi.org/10.1016/j.mayocp.2019.09.012

28. Lisnevskaia L, Murphy G, Isenberg D (2014) Systemic lupus erythematosus. Lancet [Internet]. Nov 22;384(9957):1878-88. Available from: http://dx.doi.org/10.1016/S0140-6736(14)60128-8

29. Rees F, Doherty M, Grainge MJ, Lanyon P, Zhang W. The worldwide incidence and prevalence of systemic lupus erythematosus: a systematic review of epidemiological studies. Rheumatology [Internet]. 2017 Nov 1;56(11):1945-61. Available from: http://dx.doi.org/10.1093/rheumatology/kex260

30. Lewis MJ, Jawad AS. The effect of ethnicity and genetic ancestry on the epidemiology, clinical features and outcome of systemic lupus erythematosus. Rheumatology [Internet]. 2017 Apr 1;56(suppl_1):i67-77. Available from: http://dx.doi.org/10.1093/rheumatology/kew399

31. Phuti A, Schneider M, Makan K, Tikly M, Hodkinson B. Living with systemic lupus erythematosus in South Africa: a bitter pill to swallow. Health Qual Life Outcomes [Internet]. 2019 Apr 16;17(1):65. Available from: http://dx.doi.org/10.1186/s12955-019-1132-y

32. Santos VSdos, dos Santos VS, Wiethölter P. CONTRIBUIÇÕES DA ENGENHARIA GENÉTICA NO TRATAMENTO DE DOENÇAS / CONTRIBUTIONS OF GENETIC ENGINEERING IN THE TREATMENT OF DISEASES [Internet]. Vol. 7, Brazilian Journal of Development. 2021. p. 31157-76. Available from: http://dx.doi.org/10.34117/bjdv7n3-711

33. Utiyama SR, da R, da Rosa Utiyama, de Messias Reason SR, da Silva Kotze IT LM. O sistema complemento nas doenças: genética e patogenia [Internet]. Vol. 44, Revista Brasileira de Reumatologia (2004) p. 277-86. Available from: http://dx.doi.org/10.1590/s0482-50042004000400006

\section{Tables}

Table - Demographic, clinical and laboratory comparisons among patients with SISCOM. 


\begin{tabular}{|c|c|c|c|c|c|c|}
\hline $\begin{array}{l}\text { Patients } \\
\text { Characteristics }\end{array}$ & $\begin{array}{l}\text { Total } \\
(n=26)\end{array}$ & $\begin{array}{l}\text { Amelioration } \\
(n=15,57,69 \%)\end{array}$ & $\begin{array}{l}\text { Activation } \\
(n=12,46,15 \%)\end{array}$ & $\begin{array}{l}\text { Deactivation } \\
(n=8,30,77 \%)\end{array}$ & $\begin{array}{l}\text { Worsening } \\
(n=6,23,07 \%)\end{array}$ & $\begin{array}{l}\text { Binary } \\
\text { logistic } \\
\text { regression }\end{array}$ \\
\hline $\begin{array}{l}\text { Sex, } \\
\text { female/male, n } \\
(\%)\end{array}$ & 19(73.07)/7(26.93) & $10(66.67) / 05(33.33)$ & $08(66.70) / 04(33.33)^{\star}$ & $05(62.50) / 03(37.50)$ & $04(66.67) / 02(33.33)^{\star \star}$ & $\begin{array}{l}\star[\times 2(1)= \\
5,804 ; \\
\mathrm{p}=0,041, \\
\mathrm{R} 2 \\
\text { Negelkerke } \\
=0,267] \\
\star \star[\times 2(1)= \\
9,781 ; \\
\mathrm{p}=0,008, \\
\mathrm{R} 2 \\
\text { Negelkerke } \\
=0,475]\end{array}$ \\
\hline $\begin{array}{l}\text { Age (years), } \\
\text { mean }\end{array}$ & 43.19 & 44.13 & 40.91 & 43.48 & 43.03 & NS \\
\hline $\begin{array}{l}\text { Race/ethnicity } \\
\mathrm{n}(\%) \text { (White/Non- } \\
\text { white) }\end{array}$ & $17(65.38) / 09(34.62)$ & $09(60.00) / 06(40.00)$ & 08(66.67)/04(33.33) & $04(50.00) / 04(50.00)$ & 04(66.67)/02(33.33)* & $\begin{array}{l}{[X 2(1)=} \\
7.279 ; \\
\mathrm{p}=0,020, \\
\text { R2 } \\
\text { Negelkerke } \\
=0,387]^{*}\end{array}$ \\
\hline $\begin{array}{l}\text { Age at SLE onset } \\
\text { (mean, years) }\end{array}$ & 26.05 & 28.13 & 26.33 & 27.00 & 20.67 & - \\
\hline $\begin{array}{l}\text { Age at NPSLE } \\
\text { onset (mean, } \\
\text { years) }\end{array}$ & 42.29 & 46.83 & 42.08 & 43.25 & 47.83 & - \\
\hline $\begin{array}{l}\text { Interval between } \\
\text { SLE and NPSLE } \\
\text { first symptoms } \\
\text { (mean, years) }\end{array}$ & 05.57 & 4,8 & 7,25 & 7,12 & 2,67 & - \\
\hline SLEDAl, mean & 31.69 & 33.80 & 29.83 & 29.00 & 35.00 & - \\
\hline $\begin{array}{l}\text { SLICC/ACR-DI } \\
\text { mean }\end{array}$ & 06.96 & 06.73 & 06.67 & 6.25 & 7.83 & - \\
\hline $\begin{array}{l}\text { Number of Pulse } \\
\text { Therapies, mean }\end{array}$ & 09.23 & 08.80 & 09.92 & 09.50 & 08.33 & - \\
\hline \multicolumn{7}{|l|}{$\begin{array}{l}\text { NP Manifestation } \\
n(\%) * *\end{array}$} \\
\hline Psychosis & $17(65.38)$ & $08(53.33)$ & $10(83.33)$ & $06(75.00)$ & $03(50.00)$ & NS \\
\hline Bipolar disorder & $01(3.84)$ & $01(06.67)$ & $00(00.00)$ & $01(12.50)$ & $01(16.67)$ & NS \\
\hline Depression & 07 (26.92) & $03(20.00)$ & $05(41.67)$ & $03(37.50)$ & $01(16.67)$ & NS \\
\hline Vasculitis & $02(7.69)$ & $02(13.33)$ & $00(00.00)$ & $00(00.00)$ & $02(33.33)$ & NS \\
\hline Seizure & 09 (34.61) & 05 (33.33) & 03 (25.55) & $02(25.00)$ & $03(50.00)$ & NS \\
\hline Anxiety & $06(23.07)$ & $03(20.00)$ & $03(25.00)$ & $02(25.00)$ & 02 (33.33) & NS \\
\hline Headache & $02(7.69)$ & $01(06.67)$ & $01(08.33)$ & $01(12.50)$ & 01 (16.67) & NS \\
\hline Stroke & 01 (3.84) & $01(06.67)$ & $00(00.00)$ & $00(00.00)$ & 01 (16.67) & NS \\
\hline
\end{tabular}

\section{Autoantibodies -}

$n(\%)$

Native anti-DNA

reagent/not

13/13 (50.00/50.00) 06(40.00)/09(60.00) 08(66.67)/04(33.33)

04(50.00)/04(50.00)

02(33.33)/04(66.67)

NS

reagent

ANA reagent/not

19/07 (73.07/26.93) 10(66.67)/05(33.33)

10(83.33)/02(16.67)

$06(75.00) / 02(25.00)$

$03(50.00) / 03(50.00)$

NS

Page 8/10 


\begin{tabular}{|c|c|c|c|c|c|c|}
\hline $\begin{array}{l}\text { ACA IgG } \\
\text { positive/negative } \\
(\mathrm{RV}>10 \mathrm{GPL} / \mathrm{ml})\end{array}$ & 09/13 (30.76/69.24) & $06(37.50) / 07(46.67)$ & 04(33.33)/06(50.00) & 03(37.50)/03(37.50) & 02(33.33)/03(50.00) & NS \\
\hline ACA IgG not done & $04(15.38)$ & 02(13.33) & $02(16.67)$ & $02(25.00)$ & $01(16.67)$ & - \\
\hline $\begin{array}{l}\text { ACA IgM } \\
\text { positive/negative } \\
(\mathrm{RV}>7 \mathrm{MPL} / \mathrm{ml})\end{array}$ & $13 / 09(50.09 / 40.91)$ & $09(60.00) / 04(26.67)$ & $06(50.00) / 03(25.00)$ & $02(25.00) / 04(50.00)$ & 02(33.33)/03(50.00) & NS \\
\hline $\begin{array}{l}\text { ACA IgM not } \\
\text { done }\end{array}$ & $04(15.38)$ & 02(13.33) & $03(25.00)$ & $02(25.00)$ & $01(16.67)$ & - \\
\hline $\begin{array}{l}\text { ß2GPI lgG } \\
\text { positive/negative } \\
(\mathrm{RV}>5 \mathrm{GPL} / \mathrm{ml})\end{array}$ & 05/11 (31.25/68.75) & $04(26.67) / 06(40.00)$ & $02(16.67) / 08(66.67)$ & 02(25.00)/03(37.50) & $01(16.67) / 04(66.67)$ & NS \\
\hline $\begin{array}{l}\beta 2 \mathrm{GPI} \text { IgG not } \\
\text { done }\end{array}$ & $10(38.46)$ & 05(33.33) & $02(16.67)$ & $03(37.50)$ & $01(16.67)$ & - \\
\hline $\begin{array}{l}\text { 及2GPI lgM } \\
\text { positive/negative } \\
(\mathrm{RV}>5 \mathrm{MPL} / \mathrm{ml})\end{array}$ & 07/09 (43.75/56.25) & $06(40.00) / 04(26.67)$ & $04(33.33) / 06(50.00)$ & 01(12.50)/03(37.50) & $01(16.67) / 04(66.67)$ & NS \\
\hline $\begin{array}{l}\beta 2 \mathrm{GPI} \text { IgM not } \\
\text { done }\end{array}$ & $10(38.46)$ & 05(33.33) & $02(16.67)$ & $04(50.00)$ & $01(16.67)$ & - \\
\hline $\begin{array}{l}\text { SS-B (LA) } \\
\text { positive/negative } \\
(\mathrm{RV}>20 \mathrm{U} / \mathrm{ml})\end{array}$ & 01/06 (14.29/85.71) & $01(06.67) / 06(40.00)$ & $00(00.00) / 05(41.67)$ & $00(00.00) / 05(50.00)$ & $01(16.67) / 01(16.67)$ & NS \\
\hline $\begin{array}{l}\text { SS-B (LA) not } \\
\text { done }\end{array}$ & 19(73.08) & 08(53.33) & $07(58.33)$ & 07(87.50) & $04(66.67)$ & - \\
\hline $\begin{array}{l}\text { SS-A (RO) } \\
\text { positive/negative } \\
(\mathrm{RV}>80 \mathrm{U} / \mathrm{ml})\end{array}$ & 03/07 (11.54/26.93) & 02(13.33)/08(53.33) & $00(00.00) / 06(50.00)$ & $01(12.50) / 04(50.00)$ & $00(00.00) / 02(33.33)$ & NS \\
\hline $\begin{array}{l}\text { SS-A (RO) not } \\
\text { done }\end{array}$ & $16(61.53)$ & 05(33.33) & $06(50.00)$ & 03(37.50) & $04(66.67)$ & - \\
\hline \multicolumn{7}{|l|}{$\begin{array}{l}\text { Complement - } \\
n(\%)\end{array}$} \\
\hline $\begin{array}{l}\text { C3 normal (RV } \\
0.9-1.4 \mathrm{U} / \mathrm{ml} \text { ) }\end{array}$ & $13(50.00)$ & $09(60.00)^{*}$ & $07(58,33)$ & $02(25.00)$ & $06(100.00)$ & $\begin{array}{l}{\left[\mathrm{X}^{2}(1)=\right.} \\
7.279 ; \\
\mathrm{p}=0,021, \\
\mathrm{R}^{2} \\
\text { Negelkerke } \\
=0,303]^{\star}\end{array}$ \\
\hline $\begin{array}{l}\text { C3 altered / not } \\
\text { done }\end{array}$ & 11(42.31)/02(07.69) & $\begin{array}{l}04(26.67) / \\
02(13.33)\end{array}$ & $05(41,67) / 00(00.00)$ & $06(75.00) / 00(00.00)$ & $00(00.00) / 00(00.00)$ & - \\
\hline $\begin{array}{l}\text { C4 normal (RV } \\
0.1-0.4 \mathrm{U} / \mathrm{ml})\end{array}$ & $16(61.54)$ & $10(66.67)$ & $07(58.33)$ & $06(75.00)$ & $04(66.67)$ & NS \\
\hline $\begin{array}{l}\text { C4 altered / not } \\
\text { done }\end{array}$ & $\begin{array}{l}08(30.77) / 02 \\
(07.69)\end{array}$ & $04(26.67) / 01(06.67)$ & $05(41.67) / 00(00.00)$ & $02(25.00) / 00(00.00)$ & 02(33.33) & - \\
\hline
\end{tabular}

Legend SD, standard deviation; NS, not significant; SLE, Systemic Lupus Erythematosus; NPSLE, Neuropsychiatric Systemic Lupus Erythematosus; SLEDAl, Systemic Lupus Erythematosus Disease Activity Index; SLICC/ACR-DI, Systemic Lupus International Collaborating Clinics/American College of Rheumatology. *** It is noteworthy that the same patient may have overlapping SISCOM findings.

\section{Figures}




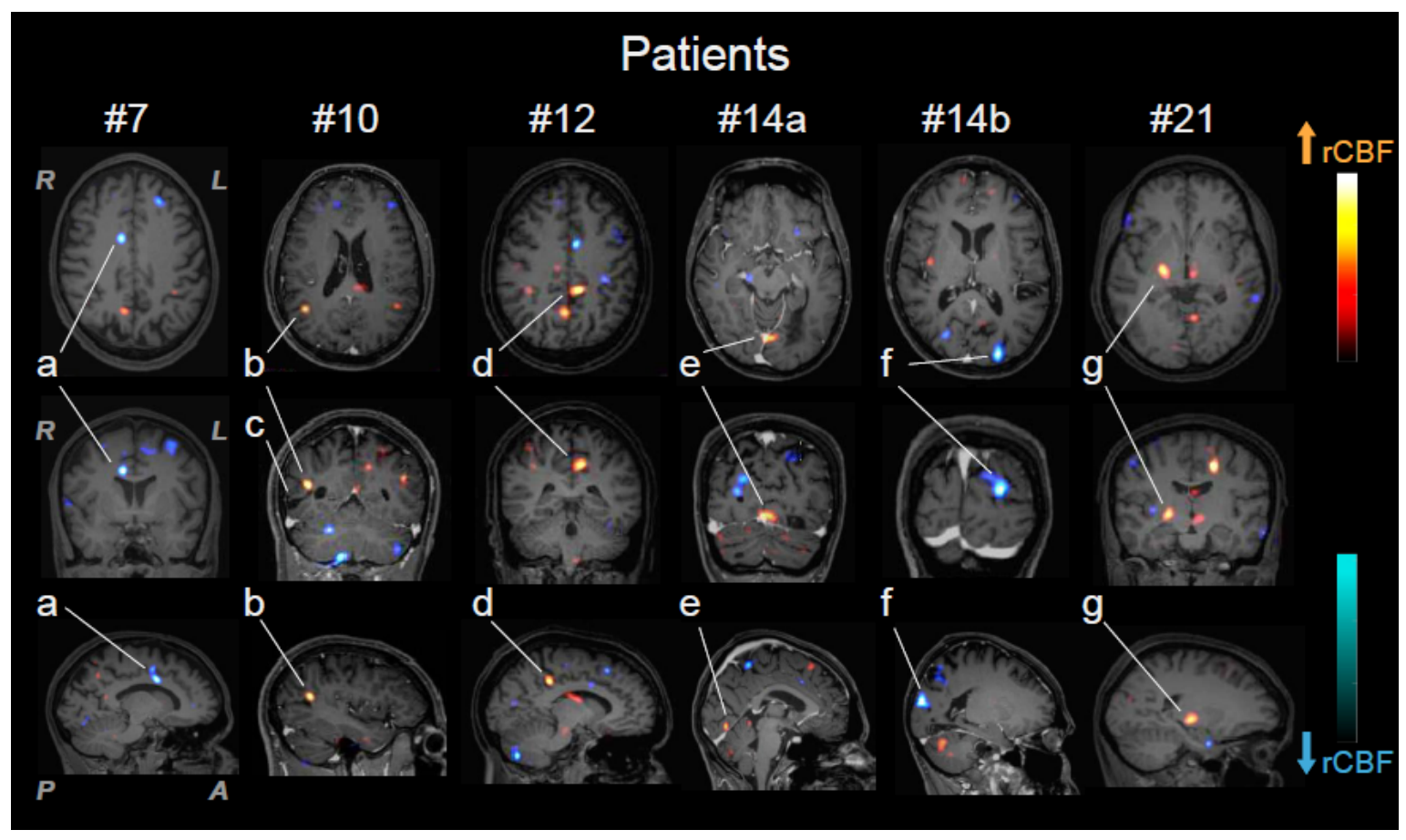

Figure 1

Subtraction SPECT coregistered to MRI (SISCOM). Patient \#7 presented decreased rCBF in the anterior cingulate cortex (a), associated with recovered anxiety, addiction and psychosis after pulse therapy. Patient \#10 presented increased rCBF in the right inferior parietal lobe (b) adjacent to a vasculitic insult (c), possibly due to luxury perfusion of the neighboring cortex after treatment, and associated to the recovery of memory and hallucinations. Patient \#12 presented increased rCBF in the precuneus, posterior cingulate cortex (d), and hypothalamus, associated with post-treatment persistent psychosis, aggressivity, and behavior modification. Patient \#14 presented two functional status after a left posterior cortex stroke: increased rCBF (e) (\#14a) in the left medial occipital lobe (reperfusion) possibly related to post-treatment recovery from the hallucinations, and decreased rCBF (f) (\#14b) in the posterior occipital lobe (worsening of ischemia). Patient \#21 presented increased rCBF overlapping with the infarcted right basal ganglia (g), possibly representing luxury perfusion, and associated with the improvement of depressive symptoms. 